\title{
¿Un intento por exportar el mercado japonés?: la revista Shonen Mangazine
}

\author{
Shonen Mangazine aldizkaria \\ Shonen Mangazine \\ Julio Andrés Gracia Lana \\ Universidad de Zaragoza \\ María Abellán Hernández \\ Universidad de Murcia
}

Merkatu japoniarra esportatzeko ahalegina?:

An attempt to export the Japanese market?:

RESUMEN: La revista Shonen Mangazine supuso un intento por parte de la editorial Planeta por plantear una revista periódica con contenido únicamente de origen japonés. Tuvo como base el auge del cómic nipón en España en la década de los años noventa, auspiciado especialmente por éxitos como Dragon Ball, de Akira Toriyama. El estudio de la estructura formal y editorial, la periodicidad y autores incluidos en el magacín, nos permite comprender mejor la historia del cómic y de la prensa periódica reciente en España.

PALABRAS CLAVE: cultura de masas; estudios culturales; industria; medios de comunicación; revista; cómic.

LABURPENA: Shonen Mangazine aldizkaria Planeta argitaletxearen proposamen bat izan zen, jatorri japoniar hutseko edukia zuen aldizkari bat sortzeko xedea zuena. Japoniako komikiek laurogeita hamarreko hamarkadan Espainian izandako goraldia hartu zuen oinarri; bereziki, Akira Toriyamaren Dragon Ball bezalako obra arrakastatsuek bultzatutakoa. Magazinaren egitura formal eta editorialaren, maiztasunaren eta bertan sartutako egileen azterketari esker, hobeto uler dezakegu komikiaren eta Espainian azken aldiko aldizkako prentsaren historia.

HITZ-GAKOAK: masen kultura; ikasketa kulturalak; industria; komunikabideak; aldizkaria; komikia. 
ABSTRACT: Shonen Mangazine supposed an attempt on the part of the publishing company Planeta to raise a periodical magazine with content solely of Japanese origin. It was based on the rise of Japanese comics in Spain in the decade of the nineties, especially sponsored by successes such as Dragon Ball by Akira Toriyama. The study of the formal and editorial structure, the periodicity and authors included in the magazine, allows us to better understand the history of the comic and the recent periodical press in Spain.

KEYWORDS: mass culture; cultural studies; industry; media; magazine; comic.

* Correspondencia a: Julio Andrés Gracia Lana. Departamento de Historia del Arte, Facultad de Filosofía y Letras, Universidad de Zaragoza. Dirección (del Dpto. y de envío): Facultad de Educación Vieja, avda. San Juan Bosco, 7 (50009, Zaragoza).jaglana@unizar.es http://orcid.org/0000-0002-2138-0554

Cómo citar: Gracia Lana, Julio Andrés; Abellán Hernández, María. 2018. ¿Un intento por exportar el mercado japonés?: la revista Shonen Mangazine. Zer. 23(45). 95-115. https://doi.org/10.1387/zer.20126

Recibido: 6 agosto 2018; aceptado: 15 octubre 2018

1137-1102 y 1989-631X / C 2018 UPV/EHU

(c) (i) Esta obra está bajo una licencia Creative Commons Atribución 4.0 Internacional 


\title{
Introducción
}

\author{
Sabíamos que una revista es algo vivo, \\ que hay que ir corrigiendo sobre la marcha. \\ Juanjo Sarto (Planeta) \\ sobre Shonen Mangazine (1995: 3)
}

El mercado del manga más allá de Japón ha ido creciendo exponencialmente desde su aterrizaje en Europa y Estados Unidos. Sin embargo, la llegada del manga al mundo editorial español estuvo preñada de circunstancias particulares y experimentaciones que hicieron que el fenómeno japonés en España arraigara de manera diferencial a otros contextos occidentales. Una de las particularidades que sin duda remarcan lo especial del contexto español fue el lanzamiento de la fórmula de la revista (tratando de acercarse al modelo japonés) en un momento en que este tipo de formato había prácticamente desaparecido entre las formas de consumo del público adulto.

Dentro de este paradigma, el presente artículo tiene un doble objetivo fundamental: analizar la revista Shonen Mangazine — como epítome de las prácticas editoriales novedosas producidas con la llegada del fenómeno manga-anime- y enmarcarla en el contexto de cambios editoriales propiciados por la llegada del cómic de origen japonés a nuestro país durante la década de los años noventa. Se parte de la hipótesis inicial de que el estudio de la estructura formal y editorial, la periodicidad y autores incluidos en la revista, nos permitirá comprender mejor la historia del cómic y de la prensa periódica reciente en España y aportará datos sobre la llegada del fenómeno manga al territorio nacional.

Dicha publicación corrió a cargo de la editorial barcelonesa Planeta y tuvo un total de veinticuatro números ordinarios, a los que se sumaron otros dos extraordinarios. Con su nombre, se hacía referencia a la revista semanal Shonen Magazine que se encuentra entre las publicaciones más icónicas de las editadas en Japón. La revista fue fundada en el año 1959 por la editorial Kodansha, uno de los grupos editoriales más relevantes a nivel internacional. Se constituyó además como uno de los primeros magacines semanales, frente a los mensuales, más característicos hasta ese momento. Actualmente, «alcanza unas ventas próximas a los tres millones de ejemplares con cada número siendo superada únicamente por su competidora Shônen Jump» (Santiago, 2010: 329).

Continuando el modelo de semanario o revista periódica seguido por productos editoriales como su homóloga japonesa, Shonen Mangazine publicó series de distintos mangas, originalmente de forma quincenal y a partir del número dieciocho 
de manera mensual. La publicación española comenzó a editarse en el año 1995, en pleno apogeo de la llegada del manga y la animación japonesa a España, y tomó el título de su referente nipón, combinando en un juego semántico la palabra de origen inglés magazine (procedente a su vez del francés magasin) con el término «manga».

El análisis del estudio de caso que nos ocupa posee una metodología eminentemente cualitativa aunque combina diferentes procedimientos. En primer lugar, se plantea una revisión crítica de la definición y conceptualización del manga como fenómeno y como producto de consumo dentro y fuera de Japón. Para comprender la dimensión del acontecimiento dentro de nuestras fronteras se revisan hitos del desarrollo mediático de España, se analiza la revista referida y se incluyen entrevistas a dos editores que tuvieron un papel fundamental en la época analizada, Antoni Guiral y Joan Navarro, además de varios cuestionarios enviados en línea a figuras que jugaron un papel clave en la publicación, el editor Antonio Martín; la redactora jefe Ana María Meca y Marika Vila, encargada de cuestiones de composición y maquetación. Los cuestionarios enviados han seguido un mismo esquema, buscando la verificación de datos sobre la publicación, tirada e impacto comunicativo y social, con especial referencia al espectro de público receptor, ahondando asimismo en las dificultades del proyecto y las causas de su cierre final.

\section{Conceptos iniciales}

Resulta necesario plantear, para empezar, una breve aclaración de tipo conceptual: el término "manga» es utilizado como sinónimo en castellano de cómic de origen japonés. Sin embargo, la definición etimológica y los orígenes culturales del manga son aún hoy discutidos (Berndt, 2009). No es hasta hace relativamente pocas décadas que el conocimiento de este medio se ha ampliado y se ha comprendido que su origen, lejos de provenir únicamente de fuentes autóctonas del archipiélago del Sol Naciente, se llevó a cabo en forma de amalgama de influencias culturales (orientales y occidentales) en distintos períodos de la historia japonesa.

Por lo tanto, el manga ha de ser entendido como una forma cultural rica, variada y dinámica (Shiokawa, 1999: 93), donde tienen cabida gran cantidad de productos que no han de ser única y exclusivamente aquellos que se importan a Occidente. Es más, el «medio del manga lleva consigo una inmensa gama de material

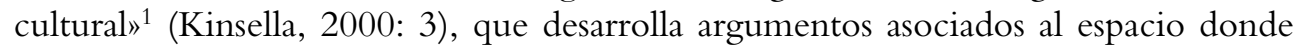
se produce la historia (instituto, pasado histórico, mundo de fantasía, ámbito laboral, etc.) y en los que la trama abarca la sátira, el drama o la aventura, por citar sólo algunos. Además de los aspectos temáticos, la narrativa propia del manga es en sí misma

${ }^{1}$ En inglés en el original: «The manga medium carries an inmense range of cultural material» (traducción propia). 
el resultado de una heterogénea mezcla con apropiaciones de fuentes visuales distintas como son «la pintura en tinta china $^{2}$, los retablos europeos con su perspectiva central, la caricatura europea y los cómics de superhéroes americanos. Después de la II Guerra Mundial todo esto fue mediado por la fotografía y el cine» ${ }^{3}$ (Berndt, 2008: 299) y aun así, habría que aunar a esta mixtura, las influencias propias venidas de los ukiyo-e y «las imágenes del mundo flotante» (Santiago, 2007; 2010), los toba-e, los emakimono y la importancia de una escritura en pictogramas (Fusanosuke, 2003).

La configuración del manga como producto y como fenómeno pasa también por considerar la industria poderosa y exigente que lo genera, donde los editores han de presionar muchas veces a los artistas para que cumplan los ajustados plazos del mercado o dirijan la narrativa hacia un punto u otro en función de las respuestas de la audiencia. De este modo, el editor (que es asignado al artista del manga, el mangaka, como si de un entrenador personal se tratara), forma parte esencial en la ideación y ejecución del relato. Según nos explica el profesor Natsume Fusanosuke:

su grado de participación [el de los editores] puede ser inimaginable en otros países. Los editores participan activamente en el proceso, y a veces ofrecen ideas para historias. Construyen relaciones personales con los mangakas, y pueden llegar a quedarse toda una noche con los autores haciendo trabajo intensivo $^{4}$ (2003: 5).

La amplitud del mercado del manga permite además la creación de un producto editorial de máxima especialización dirigido a determinados públicos cuya articulación suele basarse en la ratio de edad de los consumidores de los mismos. En este sentido, encontramos el kodomo manga (para niños), shonen manga (hombres jóvenes), shojo manga (mujeres jóvenes), seinen manga (hombres adultos) y josei manga (mujeres adultas $)^{5}$. "Los principales semanarios, que acaparan los mayores volúmenes de ventas, se inscriben en el género shônen» (Santiago, 2010: 319). Este se encuentra cons-

2 La llamada técnica del sumi-e consistía en dibujos muy aguados con tinta y pincel, donde el gesto cobra una importancia capital.

3 En inglés en el original: «...Chinese ink-painting, Europe a tableau with his central perspective, European caricature, and American superhero comics. After World War II all this was mediated by photography and film» (traducción propia).

4 En inglés en el original: "Their degree of participation in manga-making would be unimaginable in other countries. Editors actively participate in the process, and provide ideas for stories at times. They build personal relationships with the authors, and may stay up all night with authors to do intensive work» (traducción propia).

5 A esta separación habría que incluir otros subgéneros más específicos como por ejemplo el yaoi manga dirigido al público juvenil femenino o el bara manga dirigido al público homosexual masculino que obliteramos deliberadamente dada su poca incidencia dentro de la primera oleada de introducción del manga en España. 
tituido habitualmente por historias en las que prima la aventura y la acción y es también el que ha tenido, dentro del manga narrativo y comercial japonés, una mayor difusión internacional.

\section{La exportación del manga fuera de Japón}

La poderosa industria editorial nipona ha ido creciendo más allá de Japón, especialmente desde la entrada en el nuevo milenio. El consumo de este tipo de cómic se ha ido normalizando abandonando paulatinamente su estatus de producto marginal. Según el investigador José Andrés Santiago, el manga «se ha erigido como la primera manifestación cultural nipona en la actualidad» (2007: 1). A nivel global, resulta evidente que gran parte de los productos culturales y de ocio que Japón exporta (especialmente en el cruce de caminos — cross media - que se genera en su cultura popular entre videojuegos, animación y manga) cristalizan en el contexto europeo generando no sólo beneficios económicos para las casas editoras ${ }^{6}$ sino también redes de interacción entre usuarios-consumidores en forma de comunidades. Esto supone la incorporación directa del producto dentro de las formas de consumo culturales occidentales, desdibujando el aparente abismo que históricamente se ha imaginado entre Oriente y Occidente, lo que remarca la situación de globalización que se vive en la actualidad, incluso en el mundo de la historieta y el carácter universalista de las narraciones que se articulan en torno al manga narrativo (Hernández-Pérez, 2017).

Los contextos de edición de cómic europeos difieren ligeramente en sus idiosincrasias particulares. No obstante, aunque la continuidad en la actividad editorial de cómic sufra diferencias de un territorio a otro, existe un vacío evidente en el análisis de la irrupción de un fenómeno en el mundo del tebeo sin precedentes: la llegada del cómic japonés al mercado del viejo continente. Para Bouissou, Pellitrelli, Dolle-Weinkauff y Beldi (2010), esto se debe en parte a que Europa agrupa el mercado de una gran cantidad de países que contienen historias particulares y diferentes con respecto al consumo de manga. El trabajo de estos autores en su texto «Manga in Europe: A Short Study of Market and Fandom» (2010) aspira a analizar la llegada del medio a Europa centrando la atención en Italia, Francia, Alemania y Suiza para observar, aun tentativamente, los hábitos y el perfil de los lectores de manga a través de encuestas exploratorias realizadas online a comunidades fan. Al margen de las limitaciones que el estudio puede ofrecer, los resultados señalan que la consolidación del manga como producto de consumo en Europa se produce, esencialmente, en los años noventa y en combinación con la emisión de animación japonesa (conocida

${ }^{6}$ La Editorial Planeta sitúa uno de sus mangas, OnePiece (1997-) de Eiichiro Oda, como la obra con mayores ventas en todo su recorrido, cerca de 900.000 ejemplares. En Japón, One Piece lleva editados ya 82 tomos recopilatorios. 
con el término anime $)^{7}$. La industria cultural japonesa en torno al manga lleva a cabo un modelo de explotación con estrategias transmedia, de forma que el manga que obtiene el suficiente éxito suele verse arropado por otros productos que aumentan su visibilidad y rentabilidad: tomos recopilatorios, art-books (libros con ilustraciones y concept art de la serie de éxito), merchandising diverso (figuras, póster y otros pequeños objetos de consumo), animación, $\mathrm{OVA}^{8}$, doramas (teleseries de imagen real), películas de liveaction (películas que traducen a imagen real las series de animación) o videojuegos, entre otros muchos.

La conexión entre manga y anime, siendo formatos diferentes y contando ocasionalmente historias que divergen en algunas cuestiones argumentales (como ocurre en casi todas las adaptaciones), ha servido fuera de Japón para dar impulso e identidad a la cultura japonesa. "Para muchos aficionados occidentales, manga y anime forman una unidad indisociable, a pesar de gozar de un público y una especificidad propias» (Santiago, 2012: 11). El asentamiento del cómic japonés, por tanto, ha pasado en muchos contextos europeos por un diálogo entre las obras homónimas editadas en formato impreso y su emisión televisiva, llegando en ocasiones primero la versión animada antes que la editada en papel.

\section{La llegada del manga a España}

Según el trabajo de Bouissou et al., «Italia solía ser el mercado más amplio en Europa, pero las cifras de ventas oficiales no son públicas» ${ }^{9}$ (2010: 254). El inconveniente de desconocer las cifras oficiales de venta de manga es evidente también en España, donde los estudios de índices y hábitos de lectura no especifican la diferencia de consumo entre cómic de un tipo u otro. Del mismo modo que no se encuentran datos oficiales del consumo de cómic occidental u oriental mediado por variables como la edad o el género, tampoco existen cifras exactas por parte de las casas editoras que arrojen luz sobre un análisis continuado de las ventas de sus productos. Por este motivo, las aproximaciones habituales con respecto al impacto del cómic en la sociedad se definen a partir de estadísticas en el número de lanzamientos, compaginados con otros índices como el de hábitos de lectura.

Las transformaciones acontecidas en la década de los años noventa que posibilitaron la introducción del manga en España, no se contemplan en el estudio

\footnotetext{
7 «In every country, Japanese TV series have by and large been the catalyst for the uptake of manga» (Bouissou, Pellitteri, Dolle-Weinkauff y Beldi, 2010: 258).

8 Original Video Animation. Se trata de películas lanzadas directamente para televisión.

9 En inglés en el original: «Italy used to be the largest manga market in Europe, but official sales figures not made public» (traducción propia).
} 
de Bouissou, Pellitteri, Dolle-Weinkauff y Beldi y hasta el momento, carecen de aproximaciones cuantitativas. Por lo tanto, para comprender el fenómeno en el contexto nacional, debemos recurrir a fenómenos sociológicos de tipo cualitativo que traten de explicar el desembarco del fenómeno japonés en nuestro país. La transformación sociológica más obvia viene proporcionada por la conexión que se dio en el Estado español entre formato impreso y audiovisual, a la que nos referíamos unas líneas más arriba en relación al contexto europeo.

En los años ochenta, la oferta de televisión aumentó de una forma exponencial durante toda la década. En mayo de 1982 el Parlamento del País Vasco aprobó la creación de la radiotelevisión autonómica (ETB, cuya emisión comenzó en enero de 1983). Se creó además la Corporación Catalana de Radio y Televisión (CCRTV), que empezó la emisión de TV3 en mayo de 1984. Pocos años después, los habitantes de Galicia pudieron ver también en sus televisiones TVG, y en 1989 se sumaron Canal Nou en Valencia, Canal Sur en Andalucía y TM3 en la Comunidad de Madrid.

La Ley de Televisión Privada ${ }^{10}$, aprobada en 1988, presentaba una ampliación del servicio público esencial a través de la concesión de licencias de emisión por concurso. Fueron entregadas a Gestevisión Telecinco (que emitió Telecinco), Antena 3 de Televisión (que creó el canal Antena 3) y Sogecable (al que se le permitió desarrollar una cadena de pago, Canal + ).

En 1989 se creó FORTA (Bustamante, 2006: 122), una entidad que agrupaba a todas las comunidades con canal propio y que favorecía el intercambio de productos rentables entre ellas. Durante los primeros años de su andadura, hasta que la publicidad y los contratos de patrocinio generasen suficientes ingresos, los canales autonómicos optaron por una inversión lo más estoica posible. De ahí que series como Dragon Ball se repitiesen hasta la saciedad en distintos ámbitos territoriales. Antonio Martín, encargado en Planeta de la marca editorial Ediciones Forum, S.A., destaca que, en ese momento:

estaba convencido de que el éxito alcanzado por la serie de anime, especialmente en Cataluña, podía reflejarse en su edición en papel [...]. El resultado fue que en febrero de 1992 se logró alcanzar un acuerdo a través de la agencia literaria Tuttle Mori, a la que Shueisha encargó la representación de sus derechos editoriales, y que inmediatamente nos pusimos a trabajar en la edición de Dragon Ball ${ }^{11}$.

\footnotetext{
10 Nos referimos a la Ley 10/1998, de 3 de Mayo, de Televisión Privada.

11 Cuestionario general enviado a Antonio Martín a través de correo electrónico el 12/04/2016. Respondido en mayo-junio del año 2016 y en enero y marzo de 2017. Finalmente completado el $12 / 03 / 2017$.
} 
La transformación del sector televisivo y la inexistencia en un primer momento de controles sobre muchos de los derechos de explotación de las series animadas que llegaban (Hernández-Pérez, 2017: 14) promovieron un mercado subsidiario de múltiples objetos de consumo y colección, no necesariamente oficiales, asociados a la serie de éxito. Esto, en última instancia, fue generando la semilla de un gusto por las narraciones japonesas importadas del mercado europeo (especialmente Italia) que permitieron la circulación de material de origen japonés con relativa facilidad.

Pero la publicación de la serie no sólo estuvo condicionada por su éxito en formato audiovisual. A lo largo de la década de los años ochenta se produjo en España un fenómeno que eclosionó definitivamente en los noventa: la desaparición progresiva del formato revista, uno de los soportes más tradicionales y extendidos para el cómic. Los factores que potenciaron su quiebra fueron múltiples y complejos, comenzando por la competencia que en el abanico del ocio suponía el propio sector audiovisual y continuando con crisis estructurales. La suspensión de pagos de Editorial Bruguera supone un ejemplo paradigmático.

La «industria de andar por casa» (Guiral, 2012: 107), que constituía la del «tebeo» en España, sufrió un aparatoso golpe con el crack de la editorial catalana en el año 1986. Su heredera fue Ediciones B, que se hizo con el control del fondo editorial de Bruguera no mucho tiempo después. La empresa retomó la senda de su antecesora, apostando también en parte por las revistas periódicas de cómic, sin establecer, sin embargo, una renovación que podría haber llegado parcialmente desde el punto de vista editorial:

Se dice siempre que por un lado la gente se cansó de tener que comprar una revista en la que sólo aparecía a lo mejor una o dos series que le interesaban y era mejor esperar a que aparecieran en libro. Es posible. Pero también es verdad que la fórmula revista se desgastó porque no se supo llevar bien. No se supo reciclar, actualizar, modernizar el concepto. Entiendo entonces que al final la gente acabara cansándose ${ }^{12}$.

Es decir, a las transformaciones en el ámbito del ocio y los vaivenes estructurales de tipo industrial y económico, se sumaron los cambios de gusto en el público y la falta de ideas para continuar con el formato. Así, no se consiguió crear un:

Traspaso generacional, lo que fue aprovechado por otros formatos de edición, que poco a poco fueron desbancando a las revistas «para adultos» [...]. En 1993 los más jóvenes andaban ocupados en el comic-book y en el

\footnotetext{
12 Entrevista al editor y especialista en Editorial Bruguera Antoni Guiral, realizada el 06/03/2017.
} 
manga [...]. Los niños descubrieron en 1992 de la mano de Planeta DeAgostini los manga con Dragon Ball, iniciando así una relación sentimental con la historieta japonesa que pervive muy activa hoy en día (Guiral, 2011).

Díaz de Guereñu (2014: 40) insiste en esa idea, estableciendo que:

A falta de estudios de mercado, la lógica induce a suponer que revistas y álbumes no supieron atraer a los lectores más jóvenes, que prefirieron lo que ofrecían los formatos más baratos del comic book y luego del manga japonés.

\section{El boom de Dragon Ball}

Los factores anteriormente citados, abrieron de par en par la puerta al boom en los años noventa del manga en España. Al margen de vínculos puntuales anteriores, el cómic de origen japonés comenzó a adentrarse en nuestro país de forma destacada ya en los ochenta. La revista El Víbora publicó una serie de historias cortas del «diáfano» Yoshihiro Tatsumi (El Víbora, 1980: 4), mientras que en 1984 Editorial Bruguera introdujo en su semanario Lily algunas entregas del manga shojo Candy Candy, recopiladas poco después. Ese mismo año Ediciones La Cúpula, editora de El Víbora, compiló varias historias de Tatsumi en el álbum Qué triste es la vida y otras historias. Pero fue el estreno de Bola de Dragón en varios canales autonómicos y su posterior publicación en papel lo que desencadenó un auténtico boom en los noventa del fenómeno manga.

Como destaca David Hernando (director desde 2006 de la línea editorial de Planeta DeAgostini Cómics), su estreno «fue el detonante para un mercado que mueve millones hoy día» (Serrano, 2012). Marcó un auténtico punto de inflexión. Su primera emisión se produjo en TVG el 8 de febrero de 1990, doblado al gallego, y pocos días después en TV3 doblado al catalán (Santiago, 2012: 16). Poco a poco se fue extendiendo al resto de canales autonómicos. Con apenas un par de años de emisión, se consiguieron unas cifras de audiencia récord: Telemadrid llegó a obtener un $37 \%$ de share, mientras que en Valencia la cifra ascendió al 53\% y en Cataluña al 58\%. Para Daniel Quesada y Jacob García «la media era incontestable: uno de cada tres niños entre 8 y 16 años veía DragonBall» (2008: 46).

Las aventuras de Goku, un extraño chico con cola de mono que poseía poderes increíbles, fueron todo un fenómeno en España y supusieron la introducción definitiva de la cultura japonesa en las formas de consumo de los jóvenes de la época. Como señala Manuel Hernández-Pérez las aventuras de Goku resultaban un exponente claro de orientalismo debido a los rasgos característicos del relato donde los «personajes y escenarios mostraban claras influencias del folclore asiático» (2017: 16). En la trama cobraban asimismo gran importancia las artes marciales o los elementos 
tecnológicos como esencia de la coyuntura capitalista actual en Japón, que une tradición e innovación (Iwabuchi, 2002).

Considerado como violento y con cargas de erotismo muy altas para un mero «dibujo animado», su emisión trajo consigo profundas críticas por parte de algunas asociaciones de padres ${ }^{13}$. Sin embargo, no fue ningún impedimento para que acabara calando profundamente en el imaginario de toda una generación, para la que la estructura narrativa del anime cubría las necesidades de ocio. Hay que destacar también que debido al éxito de la serie animada, Planeta editó Dragon Ball fraccionando el formato tankoubon (tomo recopilatorio japonés que sirve para recoger los diferentes capítulos que son publicados en las revistas semanales) en una suerte de cuadernillos de periodicidad semanal que supusieron un éxito atroz (Pons, 2011: 269). Sobre la importancia del cómic de origen japonés, Joan Navarro destaca que: «el manga significó la salvación de Glénat Francia y también de Glénat España. De hecho, estuvo a punto de significar también que nos comiera totalmente y dejáramos de hacer otra cosa que no fuera manga». ${ }^{14}$

\section{Shonen Mangazine}

La fuerza de la que gozó el manga y un shonen como Dragon Ball en la industria, se dejó sentir en varios intentos de recuperar el formato revista, pero centrada únicamente en este sector. Ningún otro tipo de cómic podía ser capaz de constituir ex novo una revista periódica en ese momento sin que pareciera, a priori, una locura desde el prisma editorial. Camaleón Ediciones editó Ryu (1995, de un solo número) y Sukebe (1996), mientras que Norma Editorial apostó por Otaku (desde 1995). Todas estas alternativas incluyeron material de autores españoles influenciados por la estética manga y presentaron formatos editoriales diversos, en algunos casos cercanos al comic-book. Pero sin duda la mayor apuesta fue la de Planeta que, con Shonen Mangazine, publicó material de origen japonés tratando de asimilarse a la edición de manga en el archipiélago asiático y buscando constituir un auténtico magacín periódico. La idea original era crear un producto desechable, de usar y tirar, similar a los empleados en Japón. Como destaca en el número tres de la revista teórica $U$, el hijo de Urich la redactora jefe de la publicación Ana María Meca:

Como idea de diversificación del formato editorial era muy válida. Era una cosa que merecía la pena probar. Quizá en un momento se pensó de-

13 El sentir acerca de la preocupación por la violencia en los contenidos dirigidos a los niños o emitidos en la franja de horario infantil durante los años 90 se deja entrever en el artículo de Ibáñez, Pérez y Zalbidea publicado en la revista Zer en 1999.

14 Entrevista al editor Joan Navarro en Barcelona, realizada el 22/05/2017. 
masiado en el modelo japonés, en un esfuerzo de adaptar la publicación de manga en España a la publicación de manga en Japón. No pesó tanto en la decisión el que el formato revista en España sea algo muy dificil de volver a implantar. Yo aplaudo la iniciativa de que se intentara sacar una revista de esas características (Muñoz y Samaranch, 1997: 20).

Según Meca, detrás de la propuesta estaba la experiencia de un editor como Juanjo Sarto $^{15}$, que consiguió que el primer número tuviera una tirada de 15.000 ejempla$\operatorname{res}^{16}$ (fig. 1). A nivel formal, la revista encajaba dentro de la línea de magacines «de colección", propios del boom del cómic adulto y especialmente característicos de la década de los ochenta. Habían tenido importantes tiradas y transmitido ideologías y estilos de amplio impacto social. Entre ellos se encontraban Cairo o El Víbora. El primero garante de la conocida como «línea clara» y el segundo introductor en la Esfera Pública de una serie de elementos propios del underground (Crespo, 2010). De estas publicaciones apenas quedaban ejemplos en los noventa. Medían aproximadamente entre 25 y 30 centímetros de altura y de 20 a 24 centímetros de ancho. Las medidas podían, sin embargo, cambiar en función de la publicación y el momento en que se editara la misma (sobre todo en el caso de aquellas que contaban con épocas diferenciadas, en función de cambios en el editor o el director editorial). En lo que respecta al número de páginas, se movían en una amplia horquilla de entre sesenta y noventa, llegando en ocasiones a cien.

Shonen Mangazine contaba con unos 29 centímetros de alto por 20,5 de ancho, con un número total de páginas que llegaba hasta cien, constituyéndose por lo tanto como una revista bastante gruesa. A partir del número dieciocho (inclusive), la edición de la revista cambió, pasando al «lomo, una fórmula un poco más costosa de fabricación, pero que se aproxima más al "estilo" japonés» (Sarto, 1995: 3). Subió también el número de páginas (en treinta y dos más). El precio era de 550 pesetas en los diecisiete primeros números, que se convirtieron en 695 a partir del ejemplar dieciocho (inclusive). Era un coste elevado para la época, a pesar de que se utilizó un papel de baja calidad, que permitió abaratar costes.

15 Cuestionario específico sobre Shonen Mangazine enviado a Ana María Meca a través de correo electrónico el 21/06/2018. Respondido el 25/07/2018.

16 Cuestionario específico sobre Shonen Mangazine enviado a Antonio Martín a través de correo electrónico el 27/06/2018. Respondido el 23/07/2018. 


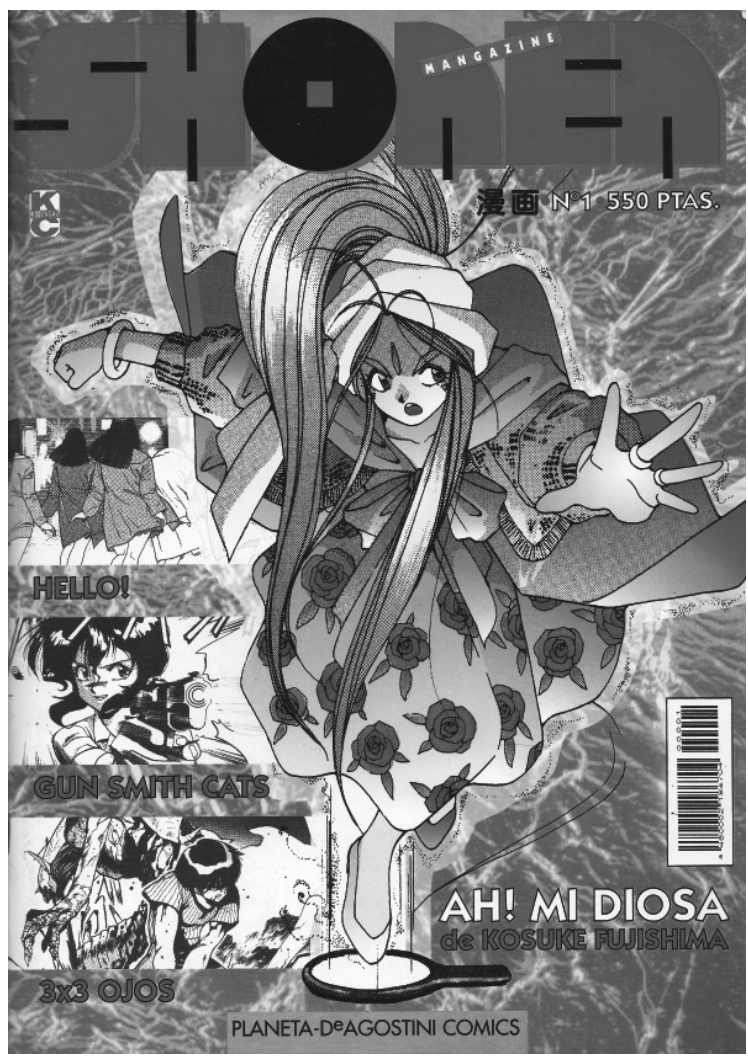

Desde el punto de vista editorial, el manga se adaptó al sentido de lectura occidental (de izquierda a derecha y de arriba abajo), lo que permitió hacer todavía más amplio un espectro de público que no resultaba de por sí nada concreto. Este hecho provocó algunas anomalías en el relato debido al habitual «efecto espejo» que se producía con estas acomodaciones. Muchos de los contenidos hacen pensar que, aunque dicho espectro era amplio, este se dirigía sobre todo a adolescentes y adultos jóvenes. En la editorial del número uno se destaca la falta de sentido que parecía tenerla utilización de la palabra shonen para definir a una revista que no estaba dirigida a un target específico:

En Japón piensan que hacemos las cosas completamente al revés. En japonés Shonen [en letra negrita en el original] quiere decir Chicos [en letra negrita en el original], y Shojo [en letra negrita en el original] significa Chicas [en letra negrita en el original]. Entonces... ¿Por qué llamarle Shonen [en letra negrita en el original] a una revista que va dirigida a todo tipo de públicos? Y, además... ¿por qué mezclamos series para jóvenes, con series para adultos, con series cómicas...? 
Hemos tenido que dar muchas explicaciones, la más importante, la del título.

Para una gran mayoría de nuestros lectores Shonen [en letra negrita en el original] es... Shonen [en letra negrita en el original] es... es... es, simplemente, una palabra japonesa, que tiene algo que ver con el manga.

$[\ldots]$

Nosotros no somos el Japón. Aquí no tenemos ninguna revista de historietas que venda seis millones de ejemplares a la semana, ni seiscientos mil, ni siquiera sesenta mil...

Aquí no podemos permitirnos el lujo de hacer una revista de historietas para oficinistas entre 20 y 35 años, o para aficionados a los deportes, o para chicas entre 12 y 16 años...

Aquí, si queremos que el Shonen Mangazine [en letra negrita en el original] se mantenga en el dificil mercado de las revistas de historietas tenemos que contar con todos y cada uno de los aficionados al manga y al anime. (Shonen Mangazine, 1995: 3).

Esta idea de definir una revista que pudiera tener un público lo más amplio posible se entreveía desde el principio hasta el fin del primer número: en la contraportada se publicitaba Promesa, de Keiko Nishi, «un manga para chicas que también gustará a los chicos» y a partir del número 19, la revista comenzó a publicar Luchadoras de Leyenda del grupo de autoras Clamp, unas mangakas cuyas historias se encuentran siempre a caballo entre el gusto femenino y masculino. Marika Vila destaca además que "ya se visualizaba la incorporación masiva de lectoras al manga, pero eso no hacía otra cosa que comenzar a equilibrar la exagerada diferencia que se ha venido dando en el cómic tradicional», de manera que "a la hora de confeccionar sus propuestas teníamos bastante más en cuenta a las lectoras que en el resto de publicaciones europeas o americanas» ${ }^{17}$. A pesar de esto, los relatos publicados provenían principalmente del mercado del manga para chicos, quizá llevados por la inercia de una industria que hacía mucho tiempo parecía haberle dado la espalda al público femenino. Se buscaba «una selecta conjunción de historias adultas para un público ya iniciado en el manga, pero con antecedentes formados en el cómic clásico europeo» ${ }^{18}$. Ana María Meca resume que:

En ese momento, el público era mayoritariamente masculino, pero en proporciones distintas a lo que podríamos considerar el público estándar del cómic en general, donde la presencia femenina no debía superar el 10-15\%.

17 Cuestionario específico sobre Shonen Mangazine enviado a Marika Vila a través de correo electrónico el 16/06/2018. Respondido el 20/06/2018. Vila fue la encargada de la realización técnica de Shonen Mangazine, con un equipo cambiante a lo largo de la andadura de la publicación.

18 Ibídem. 
Es muy aventurado dar cifras, pero en razón de la respuesta de correo y de eventos del tipo Salón del Cómic o Salón del Manga, en ese momento debíamos tener quizá un $20 \%$ de público femenino ${ }^{19}$.

Una experiencia de este tipo necesitaba un profundo contacto con los lectores, de ahí que ya desde el inicio los redactores destacaran que necesitaban:

vuestras cartas desde este mismo momento: Necesitamos saber qué series son las que más os gustan, cuáles son las que menos os interesan, qué secciones os gustaría encontrar, que pensáis del formato, del precio, de la periodicidad, de la clase de papel que utilizamos (1995: 3).

Los lectores ofrecían así a los editores una información muy valiosa. Se incluían además secciones que potenciaban el vínculo entre los aficionados, como Oriental Connection, una sección de intercambio, que apareció en Shonen Mangazine, número diez y once. Aquí, el modelo editorial que buscaba una política de implicación y valerse de la generación de una comunidad en torno a los relatos de la revista obedece totalmente la lógica de las publicaciones manga niponas.

La periodicidad, como hemos comentado líneas arriba, fue quincenal hasta el número dieciocho, pasando a partir de ese número (inclusive) a mensual. Este planteamiento suponía una apuesta editorial arriesgada, en un momento en que múltiples cabeceras mensuales, tanto infantiles y juveniles como características del boom del cómic adulto de los años setenta y ochenta, habían cerrado. A la quiebra de Editorial Bruguera, la mayor productora de revistas infantiles-juveniles hasta los ochenta, comentada líneas arriba, se sumó, por lo tanto la desaparición de publicaciones periódicas de cómic adulto. En 1995, muchas de las más paradigmáticas no se encontraban ya activas, como Cairo (1991) y Totem el Comix (fusión de Totem Magazine y de Comix Internacional, termina en 1991), mientras que Cimoc cerraría un año más tarde, en 1996. Del boom se pasó al crack, como destaca significativamente Pepo Pérez (2018: 57-93). Apostar a nivel editorial por una periodicidad tan corta al principio suponía mirar al mercado japonés, con el trasfondo del auge del manga en España, plasmado en Dragon Ball, que no se debía de creer efímero desde Planeta.

En la revista se publicó material de autores como Kosuke Fujishima, Kenichi Sonoda, Yuzo Takada, Makoto Kobayashi, Jiro Taniguchi, Kia Asamiya o Junichi Nojo, manteniendo una continuidad en las diferentes series que se publicaban, como Sobrevivir en la nueva era glacial, de Taniguchi (desde Shonen Mangazine, número cinco) o Dr. Koh de Nojo (a partir de Shonen Mangazine, número nueve).

\footnotetext{
19 Cuestionario específico sobre Shonen Mangazine enviado a Ana María Meca a través de correo electrónico el 21/06/2018. Respondido el 25/07/2018.
} 
A veces, sin embargo, la seriación se interrumpía, como en el caso de ¿Qué pasa contigo... bebé?, de Chika Tomisawa, cuyos capítulos uno y dos aparecieron en Shonen Mangazine n. ${ }^{\circ}$ 6, pero el capítulo tres no llegó hasta varios números después, en Shonen Mangazine n. ${ }^{\circ}$ 9. Acerca de los mangas incluidos, Antonio Martín destaca que en su idea inicial:

era básico que la revista publicase «mezclados» manga de las editoriales Shueisha y Kodansha, las más importantes con las que trabajábamos y con las obras más «comerciales», según nuestra experiencia con los lectores españoles. Kodansha se mostró más o menos reacia a este plan aunque abierta a discutirlo. Pero Shueisha rechazó de manera total y radical la posibilidad de que sus manga se publicasen junto con los de otra editorial en la misma revista $^{20}$.

Sobre los contenidos resulta interesante destacar además, por una parte, la diversidad. El hecho, como hemos comentado líneas arriba, de que no existiera un público concreto al que fuera dirigida la revista, permitía incluir desde el manga más humorístico, como ¿Qué pasa contigo... bebé?, pasando por la comedia romántica de $A h$ ! Mi Diosa de Kōsuke Fujishima hasta llegar a las dosis de acción y fantasía de $3 \times 3$ Ojos, de Yuzo Takada. Por otro, resulta interesante el riesgo editorial que suponía apostar por historias tan diferentes y en algunos casos alternativas. Muchas eran propuestas para atraer al lector, como en el caso de $3 \times 3$ Ojos, la obra más conocida de Takada, incluida desde el número uno. Venía además respaldada por la circulación previa del OVA distribuido por Manga Films en cuatro cintas VHS. Esta historia se encontraba protagonizada por Pai, superviviente de la raza de los 3 ojos, que poseía el secreto de la eterna juventud y la inmortalidad. ¿Qué pasa contigo... bebé? no era una propuesta tan conocida ni segura: narraba el devenir de un yakuza que se reencarnaba en el bebé de una joven pareja, dando lugar a todas las situaciones hilarantes que podían producirse con un niño interesado en la cerveza o las mujeres. La tendencia en la diversidad de las narrativas que se recogían en la Shonen Mangazine supone una muestra más del afán de impactar en un público lo más amplio posible.

Además de los capítulos de cada una de las series recogidas en la cabecera, se incluían artículos sobre Japón, acerca de los autores y que trataban el universo del manga en general, además de secciones de noticias. El sistema educativo nipón o textos que desarrollaban la vida y obra de mangakas como Shotaro Ishinomori encontraron su espacio en la revista. Entre las secciones referidas, se encontró «Japanfax», "una sección realizada a partir de noticias suministradas por Federico Colpi», traductor y especialista de origen italiano. Se vinculaban noticias llegadas desde Ja-

20 Cuestionario específico sobre Shonen Mangazine enviado a Antonio Martín a través de correo electrónico el 27/06/2018. Respondido el 23/07/2018. 
pón con lanzamientos o series que se habían editado o que se promovían desde España. Colpi destacaba noticias como que:

Acaba de anunciarse en Japón, a bombo y platillo, la aparición de Akira Club. Pero... ¿Qué es Akira Club? Los editores lo definen como un megalibro con un costo aproximado de 3.500 yens (unas 5.000 pts.) en el que se desvelará todo (iiipero absolutamente todo!!!) sobre el famosísimo manga y anime (Colpi, 1995: 99).

Uno de los apartados más destacados fue el del teórico Alfons Moliné, que contó con la completa sección "Manga y anime en España: una cronología», que recopilaba numerosos datos sobre la historia de este medio en nuestro país con especial minuciosidad, relatando la presencia de manga en los salones y en los lanzamientos editoriales o de anime en los diferentes canales de televisión españoles.

Sin embargo, el producto editorial no fue quizás bien comprendido por los lectores. En palabras de Ana María Meca: «se esperaba encontrar una revista coleccionable - que hubiera tenido otros criterios de presentación y, no nos engañemos, otro precio - o una realmente de usar y tirar, en cuyo caso fallaba quizá el precio» ${ }^{21}$. No obstante, el cierre de la revista no supuso un gran conflicto. La editorial, poseedora de los derechos de las series, relanzó muchas de las historias que había estado publicando episódicamente en la Shonen Mangazine en formato librillo (el mismo con el que había publicado Dragon Ball). De este modo en los años posteriores al cierre de la revista se continuó con la publicación de series como Gun Smith Cats de Kenichi Sonoda en su segunda etapa, Compiler de Kia Asamiya o Ah! Mi Diosa de Kosuke Fujishima.

\section{Conclusiones}

La revista resultó tan fugaz como el propio boom del manga en la década de los años noventa. Finalizó en el número veinticuatro, cuando ya era mensual y, como hemos descrito, tenía un precio más elevado que en los primeros ejemplares.

En general, la entrada del manga en Europa y España debe entenderse como un fenómeno amplio, cuya emergencia estuvo potenciada por la llegada del anime, acompañado en nuestro país por un auge del audiovisual y por un contexto industrial en el que viejos formatos, como la revista, se dejaron progresivamente atrás.

\footnotetext{
21 Cuestionario específico sobre Shonen Mangazine enviado a Ana María Meca a través de correo electrónico el 21/06/2018. Respondido el 25/07/2018.
} 
Contradictoriamente, el boom enmarcado en el anime y manga Dragon Ball llevó a la editorial Planeta a lanzar al mercado una propuesta como Shonen Mangazine, cuya estructura formal se encontraba a medio camino entre las revistas «de colección» como las del boom del cómic adulto (de las que apenas quedaban ejemplos en España en los noventa) y el magacín de consumo periódico japonés. A nivel editorial, se planteó sin un espectro de público concreto y tratando de publicar contenidos de forma estable, a la manera nipona pero con una total adaptación a Occidente (sirve como ejemplo la propia forma de lectura). La periodicidad, originalmente, quincenal, la diversificación y la inclusión de contenidos arriesgados en un mercado poco consolidado pero emergente como era el del manga en nuestro país, deben leerse con la idea de que para los editores el éxito del manga no era algo pasajero. De hecho, la editorial dijo adiós «al vehículo, que no a la mayoría de sus contenidos» (Sarto, 1996: 3).

Quizás uno de los valores de este tipo de experimento editorial no radique finalmente en su arraigo en el mercado de las revistas periódicas sino en la capacidad que tuvieron en el momento coyuntural en que aparecieron para generar un público implicado en una época de orfandad de narraciones de cómic. Se explican así revistas como Ryu, Sukebe u Otaku, antes citadas, y también la intensidad en la producción de publicaciones de difusión del fenómeno manganime y de la cultura japonesa, materializada en cabeceras de carácter más divulgativo como Dokan, Minami, Shirashe, Hentype o YaoiZone que, con distinto calado y duración, supusieron la punta de lanza para arraigar la cultura japonesa a las formas de consumo cultural populares en España. De hecho, algunas de estas revistas sirvieron también como incubadoras de dibujantes amateurs que al poco formalizaron su carrera profesional. Fue el caso de Ken Niimura o Aurora García y Diana Fernández, componentes del Studio Kôsen.

En 2009 Planeta sacó al mercado la revista B's Log Cómic, con periodicidad mensual y un formato similar a las revistas de manga japonesas, presentándose como «una revista de manga, no sobre manga» (B's Log Cómic, 2009, editorial s. p.). Sin embargo, el resultado no fue satisfactorio y resultó más perecedero que en el caso de Shonen Mangazine: sólo se pudieron mantener cuatro números. De manera similar, esta misma editorial lanzó en 2016 la revista Shojo. Especial Wataru Yoshizumi22 que contenía los capítulos iniciales de las series licenciadas en España de dicha autora, además de la primera entrega de las novedades de Yoshizumi que Planeta lanzó en ese año. El formato de la revista, al igual que B's Log Cómic se asemejaba mucho

22 Wataru Yoshizumi es la autora de series de gran éxito en España como Marmalade Boy (en España traducido como La familia crece) que supone otro exponente de anime de éxito que arrastró, finalmente, la traducción y publicación del manga en formato impreso con posteriores reediciones en formato de lujo (Kanzenban). 
más al tamaño de los magacines japoneses, incluyendo el sentido de lectura nipón de derecha a izquierda. La publicación, no obstante, parecía funcionar más como un elemento promocional y de reclamo antes que como revista en sí. Esto es, como si la revista aspirase a ser el sneak peak de las series licenciadas de la reconocida autora japonesa. Aunque Shonen Mangazine tuvo una cierta inercia a tratar de incorporar a lectoras del target femenino, lo cierto es que los editores tardaron en darse cuenta de que el mercado del manga había supuesto un aumento de este público. B's Log Cómic, con historias shojo y shonen por igual entre sus páginas, y Shojo. Especial Wataru Yoshizumi son propuestas dirigidas también a ciertos gustos del espectro de público femenino.

Sin duda, la fórmula de éxito en la publicación del manga resultó ser el tomo recopilatorio en sus distintos formatos. En relación a Shonen Mangazine y siguiendo las palabras de Meca: «precio por precio, quedó claro que las series monográficas tenían una salida mucho mayor que la revista». Bajo nuestra perspectiva esto se debe en parte al declive de la industria de la revista de cómic en España. Sin embargo, no debemos olvidar que, debido a la habitual longevidad de las series, la inversión que tanto el editor (para mantener un producto de estas características) como el aficionado debe realizar hasta completar el relato, resulta más provechosa de esta manera antes que con el consumo de capítulos breves en revistas de corta periodicidad. Los intentos por exportar elementos característicos del mercado nipón a nivel de publicaciones periódicas, se constituyen, hasta el momento, como apuestas puntuales que nos hablan acerca de la prensa periódica y del contexto del manga en nuestro país.

\section{Referencias bibliográficas}

Berndt, J. (2008). Considering Manga Discourse. Location, Ambiguity, Historicity. En M.W. MacWilliams (ed.), Japanese visual culture: explorations in the world of manga and anime (pp. 295-310). Armonk (Nueva York): Sharpe.

- (2009). Manga and "Manga»: Contemporary Japanese Comics and their Dis/similarities with Hokusai Manga. En A. Jablonski, S. Meyer y K. Morita (eds.), Civilitation of Evolution, Metamorphoses in Japan 1900-2000 (pp. 210-222). Cracovia (Polonia): Manggha/ Museum of Japanese Art and Technology.

Bouissou, J.-M.; Pellitrelli, M.; Dolle-Weinkauff, B. y Beldi, A. (2010). Manga in Europe: A Short Study of Market and Fandom. En T. Johnson-Woods (ed.). Manga. An Anthology of Global and Cultural Perspectives (pp. 253-267). Nueva York: Continuum.

B’s Log Cómic (2009). ¿Por qué B’s Log?, B’s Log Cómic, 1. Barcelona: Planeta, s. p.

Bustamante, E. (2006). Radio y televisión en España. Historia de una asignatura pendiente de la democracia. Barcelona: Gedisa Editorial.

Colpi, F. (1995). Japanfax. Shonen Mangazine, 10. Barcelona: Planeta, 99. 
Crespo Ortiz, A. (2010). El cómic español asalta la esfera pública: La revista El Víbora y el Golpe de Estado de 1981. En Zer, 28 (15), 169-179. Recuperado de http://www.ehu. eus/ojs/index.php/Zer/article/view/2358/1958

Díaz de Guereñu, J. M. (2014). Hacia un cómic de autor: A propósito de Arrugas y otras novelas gráficas. Bilbao: Universidad de Deusto.

El Víbora (1980). Editorial. El Víbora, 5. Barcelona: La Cúpula, 4.

Fusanosuke, N. (2003). Japanese Manga: Its Expression and Popularity. ABD, 34 (1), 3-5.

Guiral, A. (2011). 1970-1995: un reloj atrasado y otro tren perdido. Arbor, 187 (2), 183-208. Doi: 10.3989/arbor.2011.2extran2118. Recuperado de http://arbor.revistas.csic.es/ index.php/arbor/article/view/1376/1385

- (2012). Del tebeo al manga: Una historia de los cómics. Revistas de humor infantiles y juveniles. Barcelona: Panini España.

Hernández-Pérez, M. (2017). Manga, anime y videojuegos. Narrativa cross-media japonesa. Zaragoza: Prensas de la Universidad de Zaragoza.

Ibáñez, J.L.; Pérez, J.C. y Zalbidea, B. (1999). Televisión y programación infantil en Euskadi. En Zer, 4 (7), s. p. Recuperado de http://www.ehu.eus/ojs/index.php/Zer/ article/view/17408/15185

Iwabuchi, K. (2002). «Soft» Nationalism and Narcissism: Japanese Popular Culture goes global. En Asian Studies Re-view, 4 (26). 447-469.

Kinsella, S. (2000). Adult Manga. Culture \& Power in contemporary Japanese Society. Londres: Routledge Curzon.

Muñoz, D. y Samaranch, A. (1997). La palabra de la industria. U, el hijo de Urich, 3. Barcelona: Camaleón Ediciones, 20-25.

Pérez, P. (2018). ¿ «Solo para adultos»? Del boom al crack. La ficción de género en las revistas españolas de cómic de los ochenta. En G. Vilches (coord.). Del boom al crack. La explosión del cómic adulto en España (1977-1995)(pp. 57-92). Madrid: Diminuta Editorial.

Pons, A. (2011). La industria del cómic en España. Radiografía de ¿un mito o una realidad? Arbor. Ciencia, pensamiento, cultura, 2, Extra, 265-273. Doi: 10.3989/ arbor.2011.2extran2123

Quesada de la Cámara, D. y García Alcarria, J. (2008). Generación Dragon Ball. Palma de Mallorca: Dolmen Editorial.

Santiago, J.A. (2012). Generación manga. Auge global del imaginario manga-anime y su repercusión en España. Puertas a la lectura, 24, 10-27.

- (2010). Manga. Del cuadro flotante a la viñeta japonesa. Vigo: Grupo DxS (digital and graphic art research).

- (2007). Palabra vista, imagen leída. Certamen de Arte Gráfico para Jóvenes Creadores, Calcografia Nacional (presentación). Recuperado de http://www.jsantiago.es/jsantiago/ textos_files/Palabra\%20vista.\%20Imagen\%20lei\%CC\%81da.pdf

Sarto, J. (1995). Shonen Mangazine. Se aproximan cambios. Shonen Mangazine, 16. Barcelona: Planeta, 3. 
Sarto, J. (1996). Editorial. Aquí acaba Shonen Mangazine. Shonen Mangazine, 24. Barcelona: Planeta, 3.

Serrano, A. (2012). El manga, 20 años después de la llegada de Dragon Ball.20 minutos. Madrid. Recuperado de http://www.20minutos.es/noticia/1679290/0/manga/dragonball/sonrisa-vampiro/

Shiokawa, K. (1999). Cute but deadly: women and violence in Japanese comics. En J.A. Lent (ed.), Themes and issues in Asian Cartooning. Cute, cheap, mad and sexy (pp. 93126). Bowling Green: Bowling Green State University Popular Press.

Shonen Mangazine. (1995). Editorial. En Japón piensan que estamos locos... Shonen Mangazine, 1. Barcelona: Planeta, 3. 